\title{
Implementasi Low Interaction Honeypot Untuk Peningkatan Keamanan Server dan Analisa Serangan Pada Protokol SSH
}

\author{
Naufal Arkaan ${ }^{a}$, Dolly Virgian Shaka Yudha Sakti ${ }^{b}$ \\ ${ }^{\mathrm{a}, \mathrm{b}}$ Teknik Informatika, Universitas Budi Luhur, Jl. Ciledug Raya, Petukangan Utara, Jakarta Selatan, 12260. DKI Jakarta, Indonesia
}

\section{INFORMASI ARTIKEL}

Sejarah Artikel:

Diterima Redaksi: 02 Juli 2019

Revisi Akhir: 17 September 2019

Diterbitkan Online: 19 September 2019

\begin{tabular}{l} 
KATA KUNCI \\
\hline honeypot, \\
brute force, \\
low interaction, \\
Secure Shell, \\
network programming \\
KORESPONDENSI \\
\hline
\end{tabular}

E-mail: 1511502054@student.budiluhur.ac.id

\begin{abstract}
Faktor keamanan pada teknologi informasi saat ini sangatlah penting, dikarenakan pada zaman yang semakin berkembang data merupakan segalanya. Ancaman serangan terhadap jaringan dan server juga ikut berkembang, maka diperlukan adanya sebuah penanganan terhadap ancaman yang dapat memantau dan menganalisis ancaman serangan yang sedang berlangsung pada server. Honeypot merupakan salah satu solusi yang dapat diberikan karena merupakan sebuah sistem umpan atau aplikasi simulasi yang dapat digunakan untuk memikat penyerang dengan menyamarkan diri sebagai sistem yang rentan. Honeypot dapat digunakan untuk memantau dan menganalisis kegiatan penyerang yang tertangkap di honeypot. Honeypot ini berjenis low interaction yang dibuat menggunakan bahasa pemrograman python yang memanfaatkan konsep network programming sebagai dasarnya dan juga library paramiko untuk mengimplementasi protokol SSH yang digunakan. Honeypot berjalan di server nantinya mengakses port pada protokol SSH asli yang biasa diakses dan diserang oleh penyerang dan juga dapat menganalisis maupun memantau penyerang yang mengancam pada server. Tujuan penelitian ini adalah untuk menganalisa perilaku apa yang dilakukan penyerang di dalam server dan juga kemungkinan kemungkinan kredensial yang digunakan oleh penyerang, dengan begitu hasil dari serangan sebagai pembelajaran untuk administrator server agar server yang dikelola lebih aman.
\end{abstract}

\section{PENDAHULUAN}

Kebutuhan akan jaringan komputer semakin bertambah penting, baik dalam pendidikan, pekerjaan maupun dalam sebuah permainan, salah satu hal penting dalam mengelola jaringan komputer yaitu keamanan dari jaringan itu sendiri, dengan banyaknya akses ke jaringan tersebut maka akan banyak pula peluang kejahatan yang terjadi didalam jaringan tersebut, misalkan adanya pencurian data yang terjadi di jaringan tersebut ataupun adanya peretas yang mematikan sumber daya jaringan tersebut[1]. Kombinasi dan perpaduan keamanan software dan perangkat hardware merupakan solusi keamanan yang komprehensif. Keamanan pada jaringan komputer sebagai bagian dari sebuah sistem yang sangat penting untuk menjaga validitas dan integritas data serta menjamin ketersediaan layanan bagi penggunanya. Keamanan pada jaringan komputer harus dilindungi dari segala macam serangan dan usaha-usaha penyusupan atau pemindaian oleh pihak yang tidak berhak.

Maka dari itu perlu adanya penanganan terhadap ancaman yang dapat memantau dan menganalisis ancaman serangan yang sedang berlangsung tanpa menyentuh dan merusak server. Honeypot merupakan salah satu solusi yang dapat diberikan karena honeypot merupakan sebuah sistem umpan atau aplikasi simulasi yang mensimulasikan seluruh jaringan untuk memikat penyerang dengan menyamarkan diri sebagai sistem yang rentan[2][3], [4]. Pada beberapa penelitian, implementasi honeypot low interaction memanfaatkan dua aplikasi yang berbeda, yaitu Dionaea dan Honeyd berhasil membuat layanan palsu sebagai target serangan dan mencatat aktivitas yang dianggap dapat membahayakan sistem dan jaringan, namun tidak adanya interaksi lebih lanjut ketika penyerang berhasil mengeksploitasi dan masuk dalam honeypot [5]-[8]. Penelitian lain membahas tentang pembuatan honeypot menggunakan 
bahasa pemrograman python yang memanfaatkan package Scapy dan aplikasi $T$-Shark yang bertujuan untuk menangkap serangan pada port SMB (445) mensimulasikan pada kerentanan serangan SAMBA, memanfaatkan port 22 untuk menangkap serangan $\mathrm{SSH}$, dan memonitornya tetapi hanya sebatas interaksi terhadap port saja tanpa ada sistem yang menampung penyerang masuk kedalam SSH[9]. Berdasarkan penelitian yang sudah dilakukan tentang bagaimana honeypot berjenis low interaction diimplementasikan dan juga dibuat, maka akan dilakukan penelitian aplikasi honeypot pada server.

Aplikasi honeypot berjalan di server yang nantinya dapat menyembunyikan service port SSH asli yang biasa diakses dan diserang oleh penyerang dan juga membuat service port SSH palsu yang mampu menipu dan memantau penyerang yang mengancam pada server. Sehingga dengan honeypot, server dapat terhindar dan aman dari serangan yang dilakukan oleh penyerang. Honeypot juga meningkatkan keamanan sistem operasi. Honeypot dapat mendeteksi serangan dan mencatat serangan yang dilakukan penyerang sehingga catatan tersebut dapat dianalisa. Penyerang terhubung ke dalam port SSH palsu yang ada di honeypot. Ketika penyerang berhasil masuk, maka honeypot akan segera mengirimkan email pemberitahuan kepada administrator server.. Honeypot akan mencatat ip, port, dan aksi yang dilakukan penyerang. Setelah ada banyak penyerang yang masuk ke dalam SSH palsu dan melakukan aksinya, maka analisa dapat dilakukan dengan melihat informasi dari catatan yang dibuat oleh honeypot. Honeypot adalah sebuah sistem layanan palsu yang berfungsi untuk menjebak penyerang. Umumnya seorang penyerang di dunia jaringan mempunyai tujuan buruk yaitu melakukan pencurian atau perusakan data. Honeypot digunakan untuk menangkal usaha-usaha yang dapat merugikan sistem atau layanan[6]. Honeypot ini mengandung kerentanan sistem yang membuatnya menjadi target menarik bagi penyerang[3]. Honeypot berguna untuk pengalihan agar penyerang masuk ke server palsu dan dapat melihat log/aktivitas penyerang terhadap server[10]. Kegunaan honeypot lainnya adalah untuk mengetahui metodologi yang digunakan penyerang dalam menguasai sistem dan untuk mengumpulkan informasi sebagai bukti forensik[11].

Honeypot juga memiliki banyak manfaat seperti : (1) mitigasi risiko, (2) berfungsi seperti IDS, (3) untuk mencari tahu strategi serangan yang dilakukan oleh penyerang, (4) mengidentifikasi pelaku penyerangan serta melakukan klasifikasi, (5) sebagai bukti hukum untuk menuntut penyerang, (6) bermanfaat untuk riset yang dapat mengetahui teknik dan eksploitasi terbaru.

Honeypot terbagi dua jenis berdasarkan kegunaannya yaitu :

a. Honeypot produksi

Honeypot produksi berjenis low interaction biasanya digunakan pada server produksi oleh suatu organisasi atau perusahaan[12]

b. Honeypot penelitian

Honeypot penelitian biasanya digunakan untuk penelitian serangan yang dilakukan komunitas black hat di berbagai jaringan. Honeypot penelitian lebih rumit untuk digunakan daripada honeypot produksi karena menangkap informasi lebih banyak dan biasanya digunakan oleh penelitian, militer, dan organisasi pemerintahan[13].

Honeypot memiliki klasifikasi berdasarkan tingkat interaksinya. Tingkat interaksi dapat didefinisikan sebagai tingkat aktivitas penyerang ke dalam sistem honeypot, semakin tinggi tingkat aktivitas penyerang maka semakin tinggi pula tingkat interaksi honeypot yang harus disiapkan[14].

Berdasarkan interaksinya, terdapat dua jenis honeypot yaitu:

a. Honeypot low interaction

Honeypot low interaction menggunakan sistem operasi emulasi yang terpasang pada honeypot ketika berinteraksi dengan penyerang. Honeypot low interaction memiliki interaksi yang terbatas kepada penyerang. Serangan yang dihadapi biasanya berupa port scanning dan juga digital signature attack[13].Interaksi pada honeypot low interaction dengan host lain terbatas sehingga kemampuan yang dimiliki terbatas dan penyerang dapat dengan mudah mengenalinya tetapi dibalik terbatasnya honeypot low interaction memiliki resiko yang rendah[15].

Honeypot low interaction juga didesain untuk mensimulasikan layanan layaknya server asli dengan layanan tertentu seperti SSH. Layanan tersebut bukan sistem operasi secara keseluruhan, layanan yang berjalan tidak bisa dieksploitasi untuk mendapatkan hak akses penuh terhadap honeypot[16]. Honeypot low interaction lebih mudah diimplementasikan dan memiliki dampak resiko yang rendah pada jaringan maupun sistem[17]. Honeypot low interaction berfungsi seperti IDS pasif tanpa mengubah jalur lalu lintas jaringan yang ada[18].

Kelebihan honeypot low interaction diantaranya adalah memberikan pengalaman yang baik bagi yang belum berpengalaman dan masih dalam tahap pembelajaran membangun honeypot [19]. Kelebihan lainnya adalah untuk install, deploy, dan maintenance sangat mudah. Begitu juga dengan analisa pada log yang dihasilkan juga lebih mudah[19].

Honeypot low interaction memiliki beberapa kekurangan diantaranya: (1) log yang dihasilkan sangat terbatas, (2) kemampuan untuk menangkap serangan sudah diketahui sebelumnya, (3) dan honeypot low interaction mudah terdeteksi oleh penyerang yang sudah profesional. Tujuan dibuatnya honeypot low interaction diantaranya (1) untuk mengidentifikasi dan mendeteksi serangan yang dilakukan oleh tools otomatis, (2) menipu penyerang yang masih script kiddies, (3) mengalihkan serangan yang dilakukan oleh penyerang dari sistem asli, (4) dan mendapatkan modus serangan yang dilakukan oleh penyerang[20].

\section{b. Honeypot high interaction}

Honeypot high interaction menggunakan sistem operasi asli untuk lebih memotivasi penyerang dalam menyerang sistem sehingga strategi maupun modus serangan dapat dicatat dan dianalisis lebih detail. Honeypot high interaction mampu 
memproses dan membedakan antara paket yang bersih dengan paket yang dikirim oleh penyerang sehingga paket tersebut tidak dapat merusak server asli[13]. Kelebihan honeypot high interaction diantaranya adalah serangan yang diterima honeypot high interaction bisa jadi serangan yang asli dan belum dikenal, ini membuat serangan tersebut bermanfaat untuk dipelajari[19] Serangan yang diterima mempermudah pengguna honeypot untuk mempelajari metode yang digunakan penyerang, dan mencegah serangan pada masa mendatang dan mendapatkan pengetahuan tentang ancaman tersebut[19].

Honeypot high interaction memiliki kekurangan diantaranya untuk membuat, konfigurasi, deploy, dan maintenance memakan waktu yang lama karena harus menyesuaikan teknologi yang digunakan seperti IDS, firewall, dan lain sebagainya, Analisa serangan memakan waktu yang lama, dan Resiko yang dihasilkan oleh honeypot high interaction sangat tinggi, jika tidak ada tindakan pencegahan maupun perlindungan tambahan maka dapat merugikan organisasi dari serangan yang dilakukan oleh penyerang[19].

Tabel 1. Perbandingan Honeypot

\begin{tabular}{lll}
\hline Parameter & $\begin{array}{l}\text { Low } \\
\text { Interaction } \\
\text { Honeypot }\end{array}$ & $\begin{array}{l}\text { High } \\
\text { Interaction } \\
\text { Honeypot }\end{array}$ \\
\hline Tingkat Perkembangan & Rendah & Tinggi \\
\hline Sistem Operasi Asli & Tidak & Ya \\
\hline Resiko & Rendah & Tinggi \\
\hline Pengumpulan Informasi & Koneksi & Semua \\
\hline Emulasi Layanan & Ya & Tidak \\
\hline $\begin{array}{l}\text { Pengetahuan tentang } \\
\text { menjalankan dan } \\
\text { mengembangkan }\end{array}$ & Rendah & Tinggi \\
\hline Waktu perawatan & & \\
\hline (Sumber : Mitchell A, 2018) & Rendah & Tinggi \\
\hline
\end{tabular}

Honeypot memiliki perbedaan dengan konsep keamanan lainnya seperti firewall, intrusion detection system (IDS), anti-virus (AV), intrusion prevention system (IPS), log monitoring, dan cyber security standard. Honeypot lebih mengedepankan kepada deteksi dan reaksi tetapi kurang untuk melindungi ketika terjadi serangan[21].

Tabel 2. Perbedaan Honeypot dengan Konsep Keamanan Lainnya.

\begin{tabular}{llll}
\hline Konsep Keamanan & $\begin{array}{l}\text { Pencegah } \\
\text { an }\end{array}$ & Deteksi & Reaksi \\
\hline Honeypot & + & ++ & +++ \\
\hline Firewall & +++ & ++ & + \\
\hline IDS & + & +++ & + \\
\hline IPS & ++ & +++ & ++ \\
\hline Antivirus & ++ & ++ & ++ \\
\hline Log Monitoring & + & ++ & + \\
\hline
\end{tabular}

\begin{tabular}{|c|c|c|c|c|}
\hline $\begin{array}{l}\text { Cyber } \\
\text { Standard }\end{array}$ & Security & +++ & + & + \\
\hline
\end{tabular}

(Sumber : Nawrocki M, 2016)

Tujuan penelitian ini adalah untuk menganalisa perilaku apa yang dilakukan penyerang di dalam server dan juga kemungkinan kredensial masuk yang digunakan oleh penyerang, dengan begitu hasil dari serangan sebagai pembelajaran bagi administrator sistem untuk membuat server lebih aman.

\section{METODE}

Metode yang dilakukan memiliki beberapa tahapan yaitu studi literatur untuk pengumpulan data lalu setelah terkumpulnya data yang dibutuhkan yaitu dilakukannya analisa data untuk menganalisa apa saja yang dibutuhkan dari data yang telah didapat kemudian digambarkan dengan rancangan yang jelas untuk memenuhi kebutuhan serta pembuatan honeypot dan agar honeypot berjalan dengan semestinya dilakukanlah pengujian.

\subsection{Studi Literatur}

Metode ini menggunakan pembelajaran dengan cara mengumpulkan, membaca dan memahami jurnal ilmiah, skripsi, artikel, dan juga mencari informasi melalui forum-forum dan juga komunitas terpercaya serta referensi lain secara online guna mendapatkan informasi yang dibutuhkan dalam menunjang penelitian.

\subsection{Analisa Data}

Pada analisa data dilakukannya proses penganalisaan terhadap konsep yaitu network programming dan juga jenis honeypot yang akan diterapkan yaitu low interaction untuk mendapatkan analisa yang dibutuhkan honeypot.

2.3 Perancangan dan Pembuatan Honeypot

Perancangan dilakukan untuk memudahkan dalam mengimplementasikan rancangan honeypot dan menentukan model perangkat lunak yang bertujuan agar memberikan gambaran yang jelas honeypot yang ingin dibuat dan memenuhi kebutuhan dalam menganalisa serangan kemudian dibuatnya honeypot dari rancangan yang telah dibuat.

\subsection{Pengujian Honeypot}

Diperlukan pengujian honeypot untuk mengetahui dan menguji aplikasi agar berjalan dengan semestinya. Adapun tools yang digunakan untuk menguji aplikasi, yaitu menggunakan nmap dan hydra.

\section{HASIL DAN PEMBAHASAN}

\subsection{Rancangan Honeypot}

Pada penelitian ini protokol SSH asli pada sistem operasi dipindahkan ke port protokol lain yang diketahui oleh administrator server saja, sedangkan honeypot menggunakan port standar SSH. Penyerang yang menggunakan protokol SSH akan masuk ke dalam honeypot sehingga penyerang mengira masuk ke protokol SSH asli. Honeypot menghasilkan log yang berisi aktivitas penyerang ketika berusaha login ke dalam SSH yang 
disediakan oleh honeypot. Selain itu log akan mencatat ip, port, negara asal, kota, maupun kodepos milik penyerang. Ketika penyerang berhasil login, honeypot akan mengirimkan email berupa pemberitahuan kepada administrator server akan adanya serangan pada servernya. Seluruh kegiatan yang dilakukan oleh penyerang setelah berhasil login akan direspon oleh honeypot dan sistem operasi di dalamnya. Dibuat database yang berisi perintahperintah yang kemungkinan akan digunakan oleh penyerang ketika berhasil login

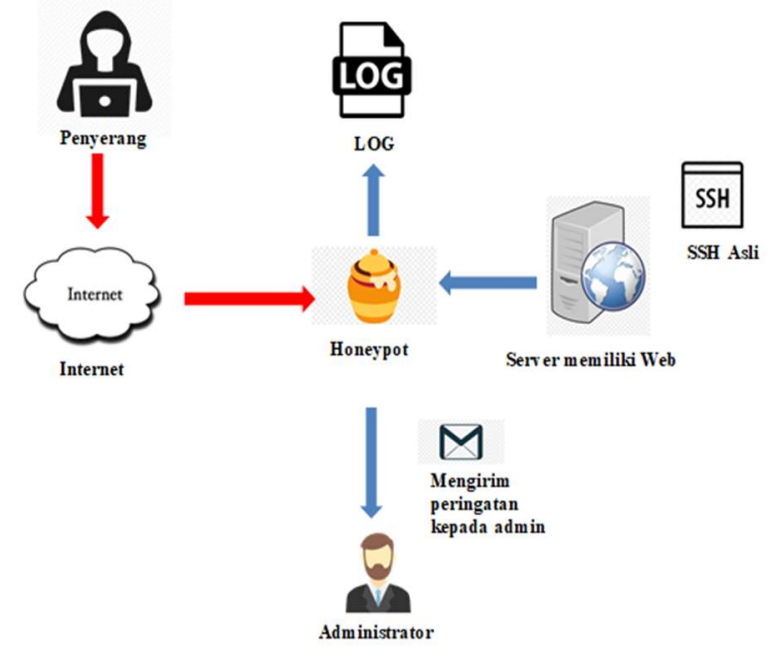

Gambar 1. Rancangan Honeypot

Gambar 2 menjelaskan ketika sistem operasi linux server menjalankan aplikasi honeypot dan penyerang terkoneksi dan sudah masuk kedalam honeypot. Honeypot memiliki database yang berfungsi sebagai kumpulan list reaksi palsu yang dibuat untuk penyerang ketika menginput sesuatu kedalam honeypot maka honeypot akan berkomunikasi dengan database lalu mengeluarkan reaksi yang ada di database sesuai input yang dilakukan oleh penyerang. Reaksi ditampilkan untuk penyerang sesuai dengan list di dalam database. Penyerang ketika menginput sesuatu tidak mengganggu sistem operasi asli, karena semua input masuk ke dalam aplikasi honeypot.

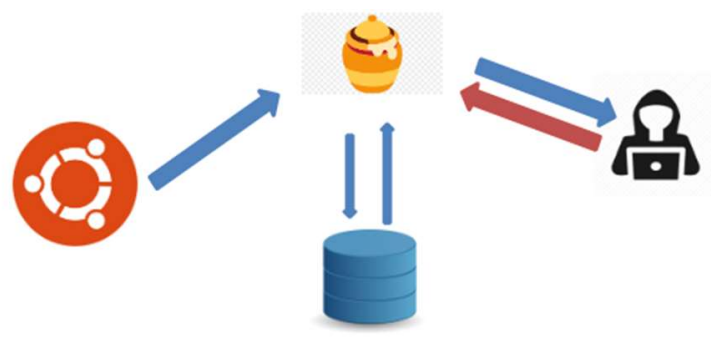

Gambar 2. Rancangan Deteksi Honeypot

\subsection{List Basis Data}

Berikut ini merupakan contoh perintah dan reaksi yang akan digunakan dan dihasilkan aplikasi honeypot yang ada pada database ketika penyerang melakukan kegiatan didalam honeypot yang telah dioperasikan, perintah ini merupakan perintah dasar pada sistem operasi Linux server sebagai berikut :

Tabel 3. List Basis Data Honeypot

\begin{tabular}{|c|c|}
\hline Input & Reaksi \\
\hline whoami & root \\
\hline pwd & / \\
\hline $\mathrm{rm}$ & $\begin{array}{l}\text { was some error in remove the files try again } \\
\text { later }\end{array}$ \\
\hline uname & $\begin{array}{l}\text { Linux server 4.11.0-32-generic \#35 20.04.1- } \\
\text { Ubuntu SMP Thu Jan 25 10:13:43 UTC } 2018 \\
\text { x86_64 GNU/Linux }\end{array}$ \\
\hline id & uid $=0$ (root) gid $=0$ (root) groups $=0$ (root) \\
\hline chmod & $\begin{array}{l}\text { : There was some error in changing access the } \\
\text { files..try again later }\end{array}$ \\
\hline chown & $\begin{array}{l}\text { There was some error in changing access the } \\
\text { files..try again later }\end{array}$ \\
\hline $\mathrm{mv}$ & $\begin{array}{l}\text { : There was some error in changing access the } \\
\text { files..try again later }\end{array}$ \\
\hline $\begin{array}{l}\text { cat } \\
\text { /etc/issue }\end{array}$ & Ubuntu 16.04 \\
\hline $\begin{array}{l}\text { cat } \\
\text { /etc/resolv. } \\
\text { conf }\end{array}$ & $\begin{array}{ll}\text { nameserver 208.67.222.222 } & \text { nameserver } \\
208.67 .220 .220 & \end{array}$ \\
\hline
\end{tabular}

List basis data bersumber dari referensi yang membahas tentang administrasi sistem operasi linux[25]. Sebagai contoh ketika seorang penyerang menggunakan command "cat letc/issue" maka aplikasi honeypot akan berkomunikasi dengan database dan database mencocokan didalam list, sehingga aplikasi honeypot akan mengeluarkan reaksi yaitu "Ubuntu 16.04". Karena jenis aplikasi honeypot bersifat low-interaction, reaksi yang dibuat tidak seperti pada sistem operasi sesungguhnya yang dapat melakukan reaksi dengan semestinya.

\subsection{Sequence Diagram}

Gambar 3 menjelaskan sequence diagram yang merepresentasikan fungsi dan aksi ketika honeypot mendeteksi adanya serangan. Sequence diagram deteksi honeypot memiliki satu aktor yaitu administrator server yang berperan untuk mengatur dan memonitoring honeypot yang berada didalam sistem operasi Linux server dan juga memiliki 16 method yaitu : (1) Open_Terminal merupakan method yang menjelaskan ketika seorang aktor yaitu administrator server mengakses terminal pada server sistem operasi Linux, (2) Run_Honeypot merupakan method yang menjelaskan ketika seorang aktor yaitu administrator server menjalankan honeypot pada server sistem operasi Linux melalui terminal, (3) Detection adalah method yang menjelaskan ketika honeypot mendeteksi adanya serangan pada server melalui protokol SSH yang dibuat oleh honeypot. (4) Logging_connection_information_attacker merupakan method yang menjelaskan ketika honeypot merekam informasi profil penyerang yang terhubung pada protokol SSH yang dibuat oleh honeypot, (5) View_connection_information_attacker adalah 
method untuk menampilkan informasi profil penyerang yang terhubung pada protokol SSH yang dibuat oleh honeypot pada terminal sistem operasi Linux server sehingga administrator server dapat melihat langsung penyerang yang masuk kedalam honeypot yang telah dijalankan pada servernya, (6) Logging_username password merupakan method yang menjelaskan ketika honeypot merekam username dan password yang dilakukan penyerang untuk mencoba login kedalam protokol SSH yang dibuat oleh honeypot, (7) Request_username_password merupakan method yang menjelaskan ketika penyerang mencoba login pada protokol SSH yang dibuat oleh honeypot menggunakan username dan password, (8) View_username_password merupakan method yang menampilkan username dan password yang telah digunakan oleh penyerang kedalam protokol SSH yang dibuat oleh honeypot sehingga administrator server dapat melihat langsung pada terminal sistem operasi Linux server miliknya, (9) Connection_accept merupakan method ketika username dan password yang digunakan penyerang untuk masuk kedalam protokol SSH yang telah disediakan oleh honeypot benar, sehingga penyerang dapat masuk kedalam server palsu honeypot, (10) Email merupakan method ketika honeypot menyiapkan email untuk mengirim kepada administrator server sebagai peringatan adanya penyerang yang berhasil masuk kedalam honeypot, (11) Email_send merupakan method untuk mengirim email kepada administrator server sebagai peringatan bahwa adanya penyerang yang berhasil masuk kedalam honeypot, (12) Email_received merupakan method ketika email peringatan diterima oleh administrator server yang dikirim oleh honeypot.

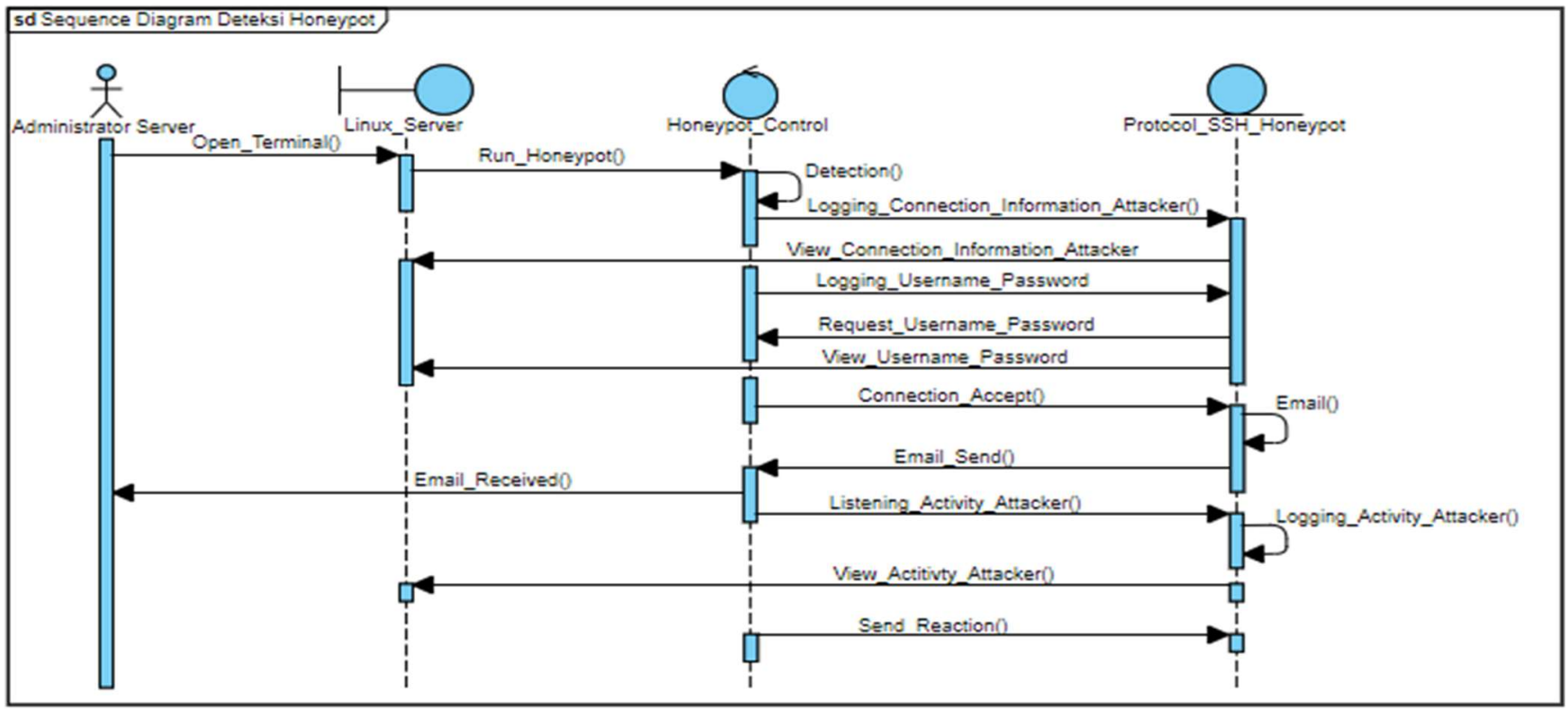

Gambar 3. Sequence Diagram Deteksi Honeypot

Listening_activity_attacker merupakan method ketika honeypot memonitoring aktifitas yang dilakukan oleh penyerang saat didalam honeypot, (13) Logging_activity_attacker merupakan method yang menjelaskan ketika honeypot mencatat aktifitas yang dilakukan oleh penyerang saat didalam honeypot, (14) View_activity_attacker merupakan method yang menampilkan aktifitas penyerang saat didalam honeypot sehingga administrator server dapat melihat langsung pada terminal sistem operasi Linux server miliknya, (15) Send_reaction merupakan method yang mengirim reaksi kepada penyerang dimana reaksi tersebut berdasarkan apapun yang dilakukan oleh penyerang didalam honeypot dan juga reaksi tersebut sudah disiapkan didalam database milik honeypot.

\subsection{Flowchart}

Pada Gambar 4 flowchart dibawah menjelaskan proses aplikasi honeypot ketika mendeteksi penyerang pada protokol SSH yang digunakan oleh honeypot. Pertama kali ketika dijalankan, honeypot mengakses port milik protokol SSH sebagai umpan untuk penyerang. Kemudian, honeypot menggunakan kunci SSH yang sudah dibuat sebagai autentikasi ketika penyerang mencoba masuk kedalam SSH yang dibuat honeypot. Lalu, honeypot terkoneksi kepada database yang telah dibuat sebagai list reaksi jika penyerang menginput sesuatu pada honeypot. Honeypot menampilkan informasi yang berarti sudah berjalan dan menunggu koneksi dari penyerang. Jika port SSH yang berarti honeypot mendapatkan koneksi dari penyerang, maka honeypot menampilkan informasi koneksi penyerang, dan jika tidak maka honeypot menunggu sampai penyerang terkoneksi pada port SSH. Setelah penyerang terkoneksi kedalam port SSH yang berarti honeypot, maka penyerang diminta username dan password untuk masuk kedalam honeypot. 


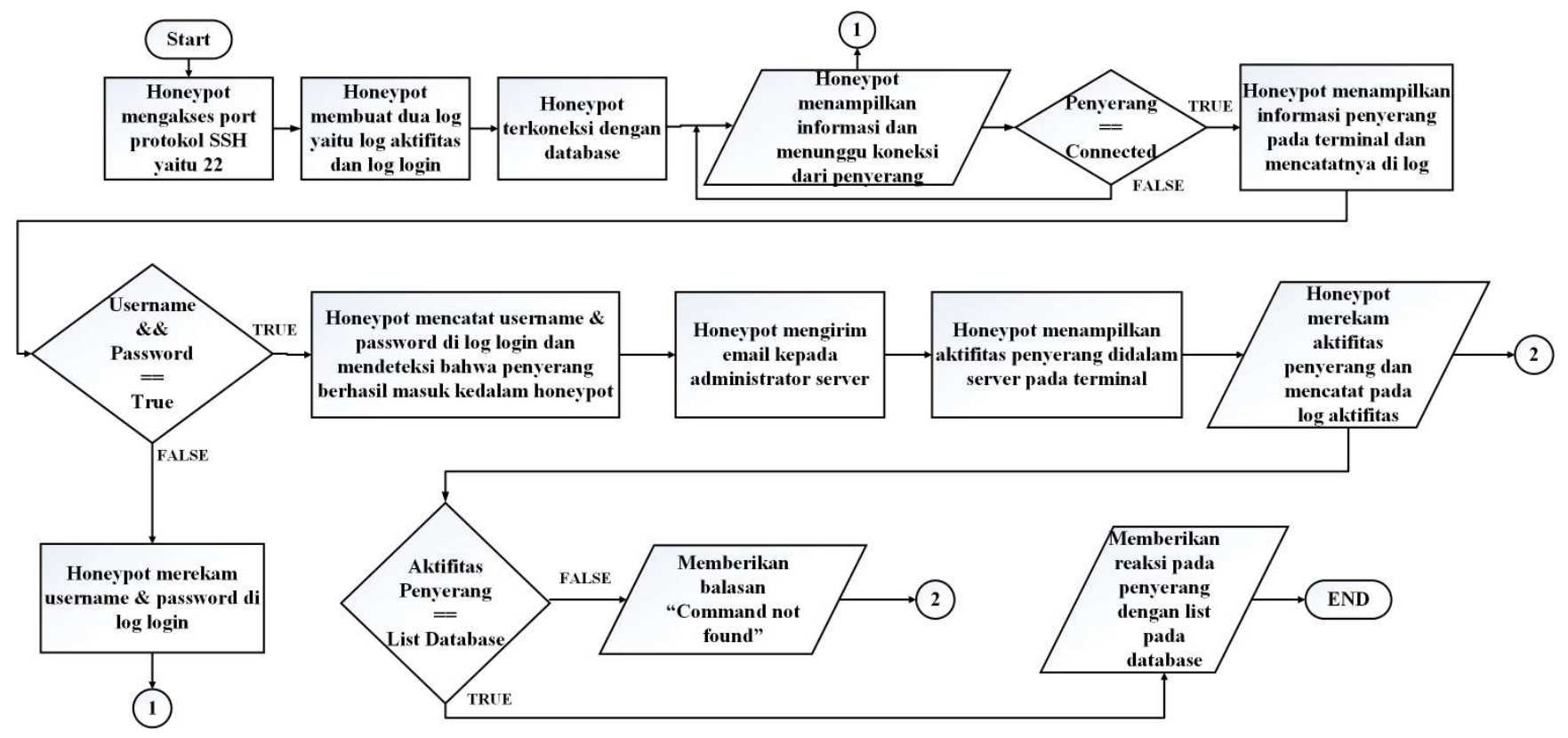

Gambar 4. Flowchart Deteksi Honeypot

Jika username dan password benar maka penyerang dapat masuk kedalam honeypot, lalu jika username dan password salah maka penyerang dapat mengulangi lagi memasukan username dan password. Username dan password yang digunakan oleh penyerang dicatat didalam log login. Ketika penyerang berhasil masuk kedalam honeypot, honeypot mengirim email kepada administrator server sebagai peringatan karena penyerang berhasil masuk kedalam honeypotnya. Honeypot menampilkan aktivitas yang dilakukan penyerang di dalam server palsu yaitu honeypot pada terminal agar dapat dilihat oleh administrator server. Setiap aktivitas yang dilakukan oleh penyerang, honeypot akan mencatat kedalam log aktivitas.

Aktivitas yang dilakukan oleh penyerang berupa suatu input yang dilakukan ketika didalam server. Aktivitas tersebut perlu ada reaksi dari honeypot agar dapat mengelabui penyerang yang seakan-akan sudah masuk ke server asli. Maka dibuatlah database yang isinya kumpulan list kemungkinan reaksi yang dilakukan ketika honeypot mendapatkan input dari penyerang. Jika input yang dilakukan oleh penyerang tidak ada di dalam list pada database maka honeypot akan menjawab "command not found" pada penyerang.

\subsection{Hasil Pengujian Serangan}

Untuk menguji coba honeypot ini dibuat skenario penyerangan pada honeypot dan juga nantinya memberikan notifikasi email jika aplikasi tersebut berjalan dengan baik dan benar.

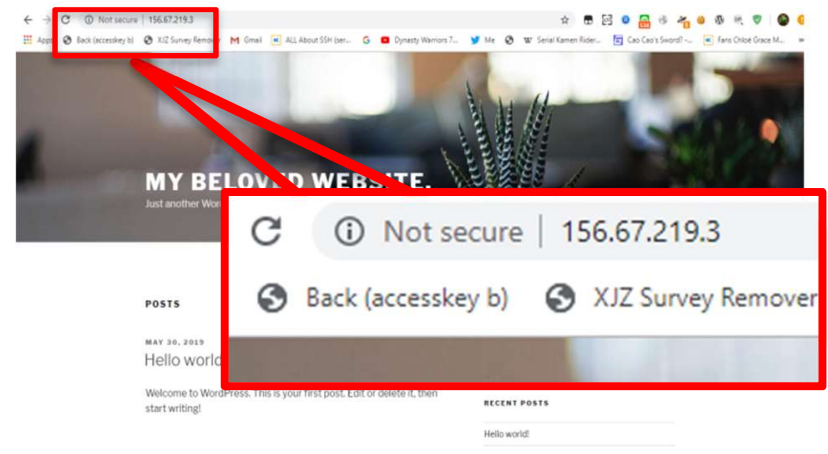

Gambar 5. Website yang dimiliki server

Gambar 5 menjelaskan server yang dijalankan memiliki service web yang dibuat menggunakan CMS Wordpress pada IP server 156.67.219.3. Untuk menghindari penyerangan pada port protokol SSH maka dipasang aplikasi honeypot pada sisi servernya.

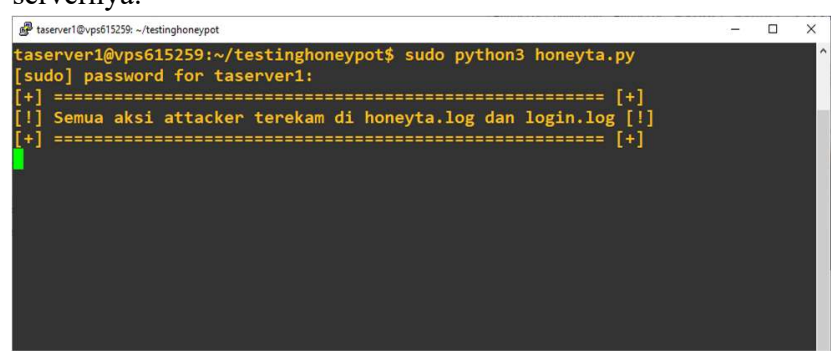

Gambar 6. Honeypot Dijalankan

Gambar 6 menjelaskan ketika menjalankan honeypot pada server. Pengguna atau administrator server menjalankan honeypot pada terminal menggunakan command "sudo python 3 honeyta.py" dan 
hasilnya honeypot berjalan lalu mengeluarkan informasi dan menunggu penyerang yang masuk pada port SSH yang dibuat oleh honeypot.

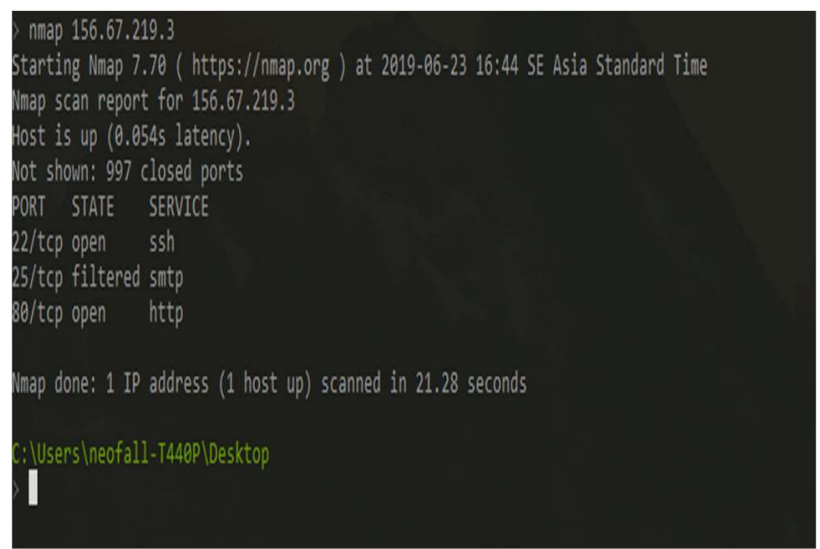

Gambar 7. Protokol SSH Honeypot ketika di Scan

Gambar 7 menjelaskan bahwa ketika IP server di scan menggunakan port scanner yaitu aplikasi nmap. Hasil scan port terdapat protokol SSH yang menggunakan nomor port 22 Protokol dengan port 22 ini adalah SSH palsu yang diakses oleh honeypot sesuai dengan source code pada honeypot pada gambar 8,gambar $9 \mathrm{SSH}$ yang asli di letakkan pada port 18000 untuk menghindari serangan langsung jika seseorang masuk melalui port 22 maka bisa dipastikan adalah serangan.

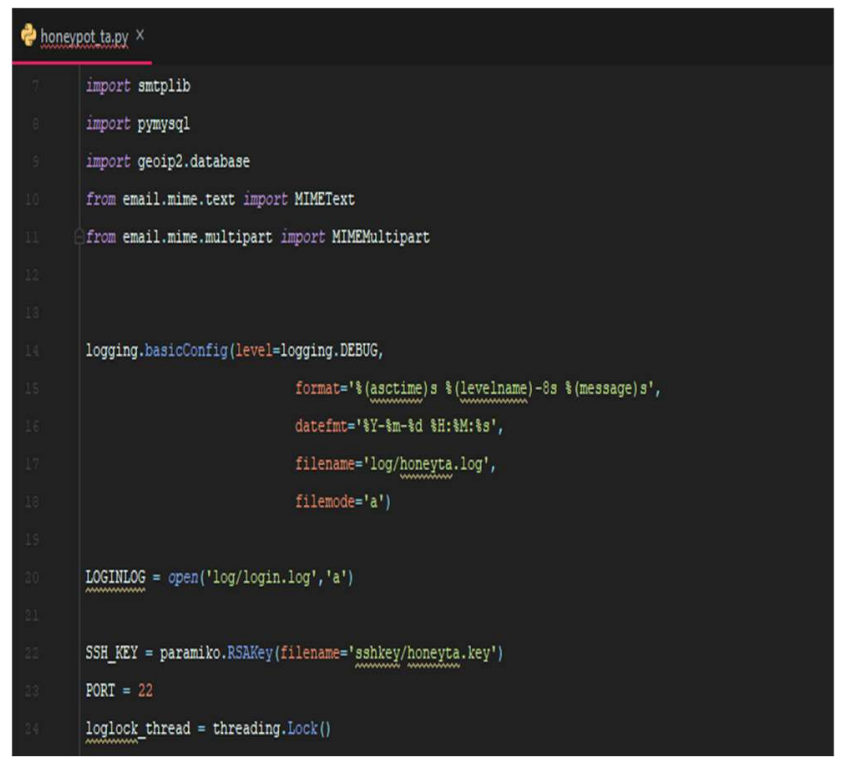

Gambar 8. Source Code Honeypot mengakses port 22

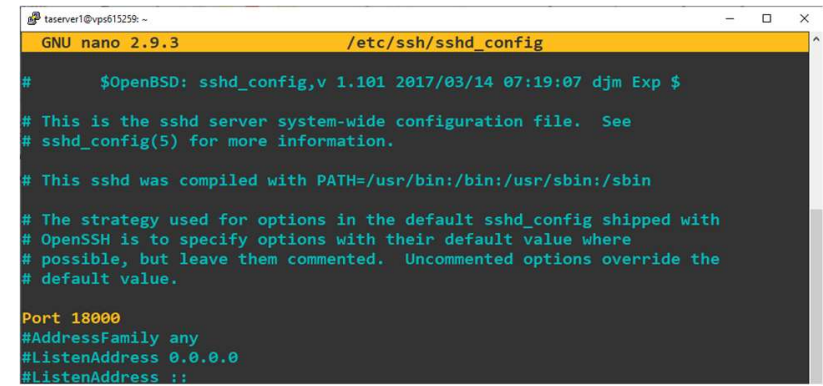

Gambar 9. Config SSH pada port 18000

Ini membuktikan bahwa pemasangan port yang dilakukan berhasil dan juga dapat membedakan serangan.

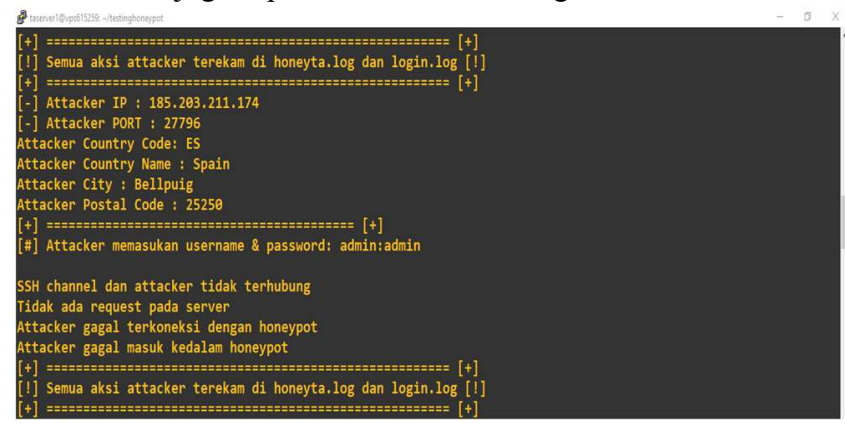

Gambar 10. Honeypot Mendeteksi Penyerang

Gambar 10 menjelaskan bahwa ketika honeypot mendeteksi adanya penyerangan terhadap port protokol SSH yang dimiliki aplikasi honeypot. Hanya saja penyerang tidak berhasil masuk kedalam aplikasi honeypot karena username dan password yang digunakan salah.

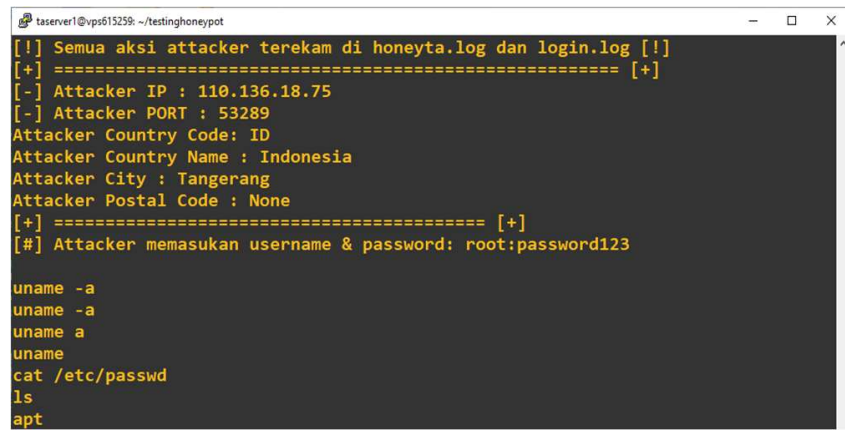

Gambar 11. Penyerang Berhasil Masuk Honeypot

Gambar 11 menjelaskan ketika penyerang berhasil masuk kedalam honeypot. Seluruh aktivitas penyerang terlihat pada layar terminal server. 


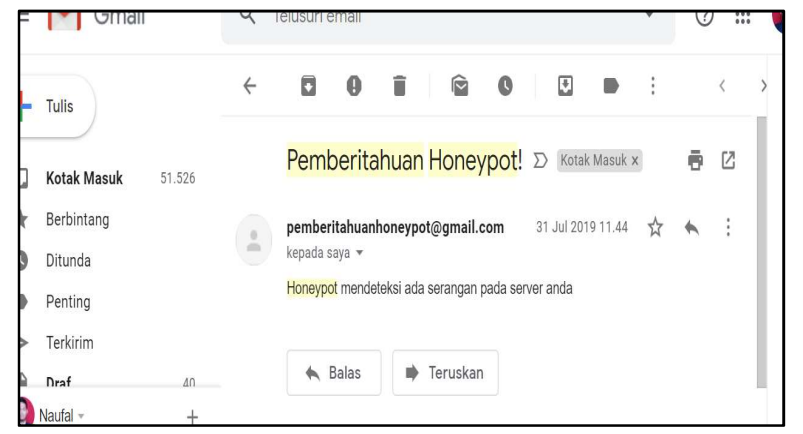

Gambar 12. Notifikasi Email Honeypot

Gambar 12 menjelaskan menjelaskan ketika penyerang berhasil masuk kedalam honeypot, honeypot mengirimkan notifikasi email kepada email administrator server untuk memberitahukan bahwa penyerang telah masuk kedalam honeypot.

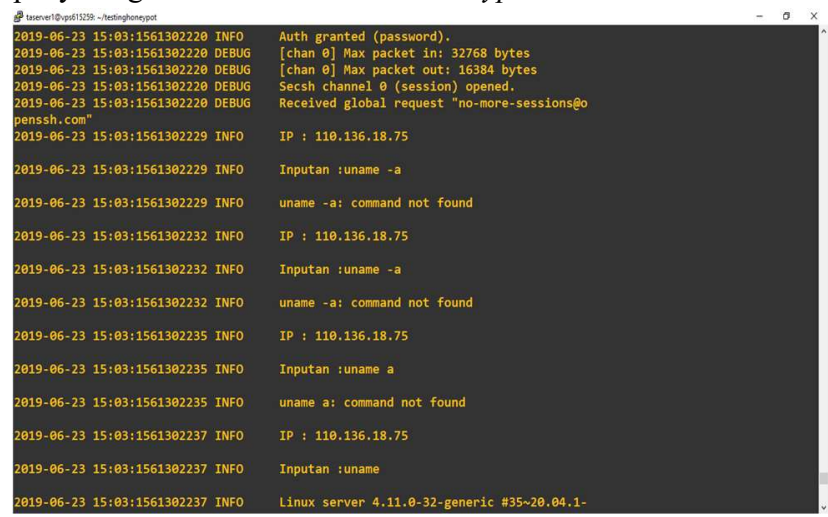

Gambar 13 : Log Honeypot

Gambar 13 menjelaskan bahwa seluruh aktivitas yang diterima dan keluaran dari honeypot terekam pada log yang dihasilkan oleh honeypot tersebut.

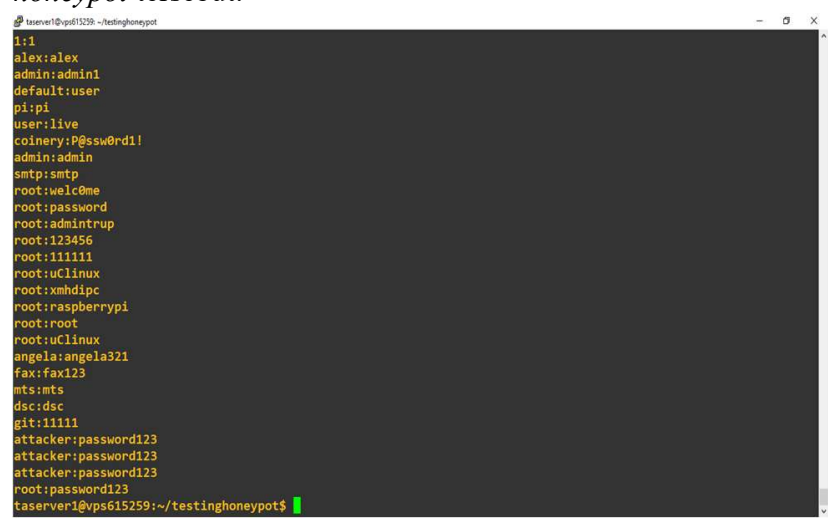

Gambar 14. Log Login Honeypot

Gambar 14 menjelaskan bahwa seluruh username dan password yang digunakan oleh penyerang terekam pada log login yang telah dihasilkan oleh aplikasi honeypot.

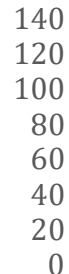

120

100

60

40

20

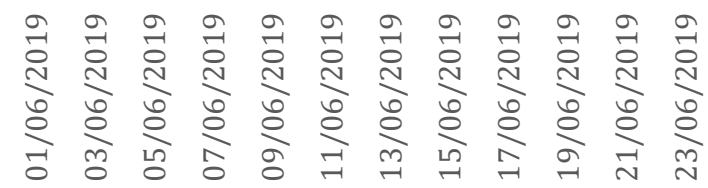

Jumlah serangan

Gambar 15. Jumlah Serangan Perhari

Pengujian yang dihasilkan membahas tentang tentang seberapa banyak command yang dieksekusi penyerangan, data username, data password, kombinasi data username dan password, dan juga negara mana saja yang telah melakukan penyerangan terhadap aplikasi honeypot. Pada gambar 15, Waktu pengujian dilakukan dari tanggal 1 sampai dengan tanggal 24 Juni 2019. Hasil keseluruhan pada data username dan password yang tercatat oleh aplikasi honeypot yaitu 327 data serangan. Hasil keseluruhan data penyerang berdasarkan negara yaitu 311 data serangan dengan jumlah 27 negara.

Tabel 4. Top 5 Username

\begin{tabular}{lll}
\hline Data Username & Jumlah & Persentase \\
\hline root & 142 & $43 \%$ \\
\hline admin & 102 & $31 \%$ \\
\hline user & 27 & $8 \%$ \\
\hline 1234 & 9 & $3 \%$ \\
\hline test & 4 & $1 \%$ \\
\hline Username Lainnya & 43 & $14 \%$ \\
\hline
\end{tabular}

Tabel 4 merupakan hasil data username terbanyak yang digunakan oleh penyerang berdasarkan hasil tangkapan dari aplikasi honeypot. Table tersebut terdiri dari data username yang selalu digunakan terus menerus dan juga data username yang berbeda. Data username yang berbeda terdiri dari nama depan, nama service, nama sistem operasi, dan juga nama-nama lainnya. Data username yang berbeda terdiri dari nama depan orang diantaranya yaitu Alex, Allan, Bernard, Eloise, Linda, Seth, dan Steve. Data username yang berbeda juga terdiri dari nama-nama service diantaranya tomcat, zimbra, nagios, weblogic, webmaster, wwwmp $2 s$, dan wwwrun.

Tabel 5 merupakan Top 5 hasil data password yang digunakan oleh penyerang berdasarkan hasil tangkapan dari aplikasi honeypot. Berbeda dari data username, data password yang digunakan oleh penyerang lebih kepada password yang berbeda. 
Tabel 5. Top 5 Password

\begin{tabular}{lll}
\hline Data Username & Jumlah & Persentase \\
\hline password123 & 11 & $3 \%$ \\
\hline admin & 7 & $2 \%$ \\
\hline 123 & 6 & $2 \%$ \\
\hline password & 6 & $2 \%$ \\
\hline 1234 & 5 & $2 \%$ \\
\hline Password Lainnya & 294 & $89 \%$ \\
\hline
\end{tabular}

Tabel 6. Top 5 Kombinasi Username dan Password

\begin{tabular}{lll}
\hline Data Username & Jumlah & Persentase \\
\hline root/password123 & 10 & $3 \%$ \\
\hline $\operatorname{root} / 0$ & 2 & $1 \%$ \\
\hline $\operatorname{admin} / 1234$ & 2 & $1 \%$ \\
\hline $\operatorname{root} / 111111$ & 2 & $1 \%$ \\
\hline $\operatorname{root} / 987654321$ & 2 & $1 \%$ \\
\hline $\begin{array}{l}\text { Username/Password } \\
\text { Lainnya }\end{array}$ & 310 & $93 \%$ \\
\hline
\end{tabular}

Tabel 6 merupakan lima hasil pengujian data dari kombinasi username dan password yang digunakan oleh penyerang berdasarkan hasil tangkapan dari aplikasi honeypot. Kombinasi username dan password yang digunakan oleh penyerang sebagian besar menggunakan root. Kombinasi username dan password paling banyak digunakan yaitu root/password123 yang juga merupakan kombinasi yang sah untuk masuk kedalam aplikasi honeypot.

Tabel 7. Top 5 penyerangan berdasarkan negara

\begin{tabular}{lll}
\hline Data Username & Jumlah & Persentase \\
\hline Indonesia & 101 & $33 \%$ \\
\hline Cina & 42 & $13 \%$ \\
\hline Amerika & 31 & $10 \%$ \\
\hline Panama & 19 & $6 \%$ \\
\hline Rusia & 17 & $5 \%$ \\
\hline Negara Lainnya & 101 & $33 \%$ \\
\hline
\end{tabular}

Tabel 7 merupakan lima negara asal penyerang dengan jumlah serangan terbanyak. Negara yang tercatat pada tabel paling banyak dan juga konsisten melakukan serangan yang tercatat pada aplikasi honeypot adalah Indonesia. Negara yang tercatat pada aplikasi honeypot setelah Indonesia yaitu Cina, Amerika, Panama, dan Rusia. Negara yang tercatat pada aplikasi honeypot lainnya seperti Prancis, Spanyol, Brazil, Kanada, Belanda, Jerman, Romania, Singapura, Argentina, India, Korea Selatan, Vietnam, Meksiko, Colombia, Ukraina, Mozambique, Polandia, Ekuador, Denmark, Swedia, Irlandia, dan Thailand.
Tabel 8. Command yang Dieksekusi Penyerang

\begin{tabular}{ll}
\hline Data Command & Jumlah \\
\hline ls & 9 \\
\hline sudo su & 3 \\
\hline clear & 3 \\
\hline uname -a & 2 \\
\hline uname & 2 \\
\hline uname a & 1 \\
\hline ls -a & 1 \\
\hline apt & 1 \\
\hline wget https://github.com/FireFart/dirtycow & 1 \\
\hline wget & 1 \\
\hline cat /etc/passwd & 1 \\
\hline cls & 1 \\
\hline nmap & 1 \\
\hline -h & 1 \\
\hline -help & 1 \\
\hline --help & 1 \\
\hline root & 1 \\
\hline whoami & 1 \\
\hline fix & 1 \\
\hline ls /usr/bin & 1 \\
\hline sudo & 1 \\
\hline &
\end{tabular}

Tabel 8 merupakan hasil command yang dieksekusi oleh penyerang ketika didalam aplikasi honeypot. Hasil command yang dieksekusi yang digunakan oleh penyerang paling banyak adalah command " $l s$ " yang berguna untuk melihat daftar direktori yang ada pada server. Hasil data yang menarik disini adalah ketika penyerang mengeksekusi command "wget https://github.com/FireFart/dirtycow" yang berguna untuk mendownload suatu malicious code atau kode jahat yang digunakan untuk memperoleh akses root dan menguasai server. Hasil command yang dieksekusi lainnya kebanyakan hanya untuk mengidentifikasi informasi yang ada di dalam server.

\section{KESIMPULAN}

Dari hasil pengujian dapat disimpulkan bahwa honeypot yang dibuat menggunakan SSH server palsu atau SSH tiruan yang untuk mengelabui penyerang sehingga penyerang tidak menyerang SSH server yang asli. Honeypot yang dibuat membantu meningkatkan keamanan pada server. Honeypot yang dibuat menangkap username dan password yang digunakan penyerang untuk masuk ke dalam server agar administrator server lebih memperkuat login credentials pada SSH lalu mendeteksi adanya serangan brute force berupa login credentials yang dikirim terus menerus yang dilakukan oleh penyerang. Honeypot mencatat data username dan password secara keseluruhan yaitu 327 data serangan. Hasil keseluruhan data penyerang berdasarkan negara yaitu 311 data serangan dengan jumlah 27 negara yang tercatat dan ditangkap oleh honeypot. Penyerang yang masuk 
kedalam honeypot rata-rata mencari tahu informasi direktori yang ada didalam sistem operasi. Ditemukan pada log honeypot penyerang berusaha mengunduh code exploit Dirtycow yang berfungsi untuk menguasai server.

\section{DAFTAR PUSTAKA}

[1] O. K. Sulaiman, "Analisis Sistem Keamanan Jaringan dengan Menggunakan Switch Port Security," CESS (Journal Of Computer Engineering, System And Science), Jan. 2016.

[2] C. K. Ng, L. Pan, and Y. Xiang, Honeypot Frameworks and Their Applications: A New Framework. Springer, 2018.

[3] M. M. Mustofa and E. Aribowo, "Penerapan Sistem Keamanan Honeypot Dan IDS Pada Jaringan Nirkabel (Hotspot)," Jurnal Sarjana Teknik Informatika, vol. 1, no. 1, pp. 111-118, 2013.

[4] A. Zainuddin, L. Affandi, and A. D. Susilo, "Analisis Sistem Keamanan Hotspot Dengan Menggunakan Honeypot Dan IDS Di Kampus STMIK PPKIA PRADNYA PARAMITA Malang," JURNAL TEKNOLOGI INFORMASI: Teori, Konsep, dan Implementasi, vol. 5, no. 2, pp. 107-112, 2014.

[5] A. F. Nurrahman, "Implementasi Virtual Low-Interaction Honeypot Dengan Dionea Untuk Mendukung Keamanan Jaringan," Journal of Informatics and Technology, vol. 2, no. 4, pp. 28-37, Sep. 2014.

[6] A. S. Nugroho, S. Raharjo, and J. Triyono, "Analisis dan Implementasi Honeypot Menggunakan Honeyd Sebagai Alat Bantu Pengumpulan Informasi Aktivitas Serangan pada Jaringan,” Jurnal JARKOM, vol. 1, no. 1, pp. 40-48, Dec. 2013.

[7] T. A. Cahyanto, H. Oktavianto, and A. W. Royan, "Analisis dan Implementasi Honeypot Menggunakan Dionaea Sebagai Penunjang Keamanan Jaringan," JUSTINDO (Jurnal Sistem dan Teknologi Informasi Indonesia), vol. 1, no. 2, May 2017.

[8] N. Fitriana and F. N. Khasanah, "Honeypot Menggunakan Honeyd Sebagai Solusi Keamanan Jaringan Dari Aktivitas Serangan,” Bina Insani ICT Journal, vol. 5, no. 2, pp. 143-152, Dec. 2018

[9] A. Mitchell, "An Intelligent Honeypot," Cork Institute of Technology, 2018.

[10] W. Wilman, I. Fitri, and N. D. Nathasia, "Port Knocking Dan Honeypot Sebagai Keamanan Jaringan Pada Server Ubuntu Virtual," J I M P - Jurnal Informatika Merdeka Pasuruan, vol. 3, no. 1, Mar. 2018.

[11] V. Malik, M. Jhawar, Harleen, A. Khanijau, and N. Chawla, "LAN Based Intrusion Detection And Alerts," IJSTR, May 2014.

[12] D. X. Gkoutzelis and M. S. Sardis, "Web Server Security on Open Source Environments," in Next Generation Society. Technological and Legal Issues, 2010, pp. 236247.
[13] R. Upadhayay, T. K. Mandal, S. Joshi, and M. Kala, "Data Security Using Honeypot," IJIRT, Apr. 2017.

[14] R. K. Singh and T. Ramanujam, "Intrusion Detection System Using Advanced Honeypots," International Journal of Computer Science and Information Security, vol. 2, no. 1, 2009.

[15] A. Jain and D. B. Buksh, "Advance Trends in Network Security with Honeypot and its Comparative Study with other Techniques," International Journal of Engineering Trends and Technology, vol. 29, pp. 304-312, 2015.

[16] B. Tambunan, W. S. Raharjo, and J. Purwadi, "Desain dan Implementasi Honeypot dengan Fwsnort dan PSAD Sebagai Intrusion Prevention System," ULTIMA Computing, Sep. 2013.

[17] S. Z. Melese and P. S. Avadhani, "Honeypot System for Attacks on SSH Protocol," I. J. Computer Network and Information Security, Sep. 2016.

[18] N. Kambow and L. K. Passi, "Honeypots: The Need of Network Security," IJCSIT, 2014.

[19] S. Gupta and V. Singhal, "Honeypot a Trap for Hackers," INDIACom, 2011.

[20] R. C. Joshi and A. Sardana, Honeypots A New Paradigm to Information Security. New York: Science Publishers, 2011.

[21] M. Nawrocki, M. Wählisch, T. C. Schmidt, C. Keil, and J. Schönfelder, "A Survey on Honeypot Software and Data Analysis," arXiv [cs.CR], 22-Aug-2016.

[22] D. Matotek, J. Turnbull, and P. Lieverdink, Pro Linux System Administration: Learn to Build Systems for Your Business Using Free and Open Source Software. New York: Apress, Berkeley, CA, 2017.

\section{BIODATA PENULIS}

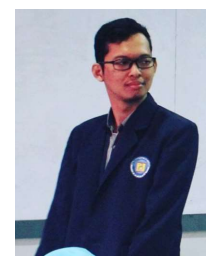

Naufal Arkaan

Penulis merupakan mahasiswa sarjana Universitas Budi Luhur Fakultas Teknologi Informasi. Jurusan Teknik Informatika dengan peminatan Network \& Web Security.

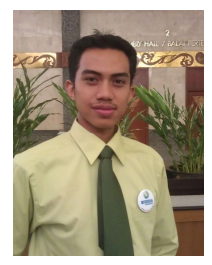

Dolly Virgian Shaka Yudha Sakti

Kontributor merupakan dosen pada Program Studi Teknik Informatika Universitas Budi Luhur. Tertarik pada penelitian bidang kriptografi, keamanan komputer, dan computer science. 